\title{
Does Price Promotion Hurt Products' Perceived Quality? The Role of Attribute Alignability
}

\author{
Myoung-Jin CHAE ${ }^{1}$
}

Received: August 10, 2020. Revised: August 31, 2020. Accepted: September 16, 2020.

\begin{abstract}
Purpose: Previous literature shows that a price promotion serves as a negative cue of product quality especially when consumers have no additional information about the product's other attributes. In this research, we explore how the effect of price promotions on consumers' perceptions of product quality changes depending on their ability to compare promoted product attributes with competitive products' attributes. Research design, data and methodology: Specifically, we use a series of scenario-based lab experiments using different types of products and explore if attribute alignability among competing products in a consumer's choice set influences consumers' ability to compare the product attributes and perceived quality. Results: Our study findings show that high attribute alignability among products makes consumers easier to compare the product attributes and thereby focus more on non-price information than price information. We also show that attribute alignability serves as a moderator and decreases perceived quality when the promotion level is higher. Therefore, the attribute alignability weakens the negative impact of a price promotion on consumers' perceived product quality. Conclusions: Our study findings provide new insights on how to implement price promotion strategies while keeping products' perceived quality, by considering the product's relationships with competing products in a choice set.
\end{abstract}

Keywords : Price Promotion, Perceived Quality, Attribute Alignability, Consumer Choice

JEL Classification Code: D91, M31, M30, L11

\section{Introduction}

Sales promotion is the important component of the marketing practice which attracts consumers. Since its effect on sales is tangible (i.e., can be seen) and immediate, it is often appealing to result-oriented firms (Neslin, 2002). Firms use various types of sales promotions to attract consumers and their effect on sales and consumers' attitudes to products varies. While sales promotion can be categorized into monetary promotion and non-monetary promotion - i.e., monetary promotion as a type of monetary benefit a firm offers, such as a discount coupon or a free coupon and non-monetary promotion as a type of non-monetary reward a firm offers, such as an offer of a membership or a free gift, this research will focus only on monetary promotion, in particular, a price discount and its impact on consumers' perceived product's quality.

1 First Author. Assistant Professor, Department of Marketing and International Business, Lingnan University, Hong Kong. Email: jinnychae@gmail.com

(c) Copyright: The Author(s)

作 unrestricted noncommercial use, distribution, and reproduction in any medium, provided the original work is properly cited. 
"The cheaper the better." It is easily imagined that consumers usually look for the lowest price available among several options offering different prices, and they always want to get as much of a discount as possible. It is more beneficial for consumers if they get more of a discount as it means they are able to purchase products with lower cost (price). Promotion is also beneficial for firms in several ways. If a firm offers a discount in the market where its competitors are selling the same products, the firm can attract consumers by providing a better offer (i.e., a lower price) and making them switch from other brands/stores. Gupta (1988) found that consumers' brand switching behavior accounted for the largest part of increase in sales due to promotion, while purchase acceleration and stockpiling accounted for less than $20 \%$ of the increase. In addition, even if a consumer is reluctant to purchase a product because he or she is not sure whether it is worthwhile to purchase, a firm's discount offer can increase the likelihood of purchase by reducing cost. In line with this idea, the positive impact of price promotion on sales in the short-term has been studied (Blattberg \& Neslin, 1990).

However, promotion is not always beneficial to both consumers and firms. Some of the prior research suggests there is also a negative impact of promotion on consumer's perception of a product and firms' sales. Several factors have been found to be negatively related with a firm's promotion. For example, a consumer's brand evaluation is lower when that brand is promoted (Raghubir \& Corfman, 1999; Davis, Inman, \& McAlister, 1992). Also, the amount which consumers are expected to pay for a brand or product is reduced by an increase in the frequency/depth of price promotions of the brand observed by the consumers (Kalwani \& Yim, 1992). In terms of sales, the probability of repeat purchase of a brand after one's purchase on promotion is found to be smaller than the corresponding value after a purchase not on promotion (i.e., purchase at regular price) (Dodson, Tybout, \& Sternthal, 1978).

Earlier findings on the positive and negative effects of promotions in the literature suggest that promotion attracts consumers, positively influences consumers' perception for an offer/deal, and increases the likelihood of purchase of a product, which leads to an increase in short-term sales. On the other hand, as promotion becomes deeper or more frequent, a consumer's overall evaluation of a product can be undermined. When consumers' overall perception of product quality decreases, it could result in a decrease in sales or undermining customer loyalty to a brand in the long term.

In this research, we explore the circumstances when a price promotion has less negative consequences. We start our theory development by introducing the concept of consumers' perception of product quality distinct from objective quality and introduce previous research findings on the negative effect of a price promotion on consumers' perceived product quality. Next, we introduce the concept of attribute alignability in a choice set and show how it influences consumers' ability to compare options in their choice set. Then, we argue that attribute alignability in consumers' choice set influences the negative impact of a price promotion on consumers' perceived quality of a product. Finally, theoretical and managerial contributions and limitations of the research are followed.

\section{Theory Development}

\subsection{Consumers' Perceived Product Quality}

Perceived quality is "the customer's perception of the overall quality or superiority of a product or service with respect to its intended purpose, relative to alternatives”, defined by Aaker (2009). Researchers (e.g., Dodds \& Monroe, 1984; Garvin, 1984) emphasize that perceived quality is a different concept from objective quality. That is, objective quality is used to explain the actual technical superiority or excellence of the products (Monroe \& Krishnan, 1985; Hjorth-Anderson, 1984), which implies that it is a measurable in terms of superiority on some predetermined standards.

While perceived quality is closely associated with objective quality, they are not identical, in that managers' views of products may differ from consumers' views (Zeithmal, 1988). Lichtenstien and Burton (1989) found a positive relationship between perceived quality and objective quality, but they show that the relationship is strengthened or weakened by individual characteristics and product categories. We argue that consumers' perceived quality is an important concept in that often times the way firms measure product's objective quality is different from the way consumers' perceive product quality. Without acknowledging the gap between objective quality and perceived quality, managers might end up delivering different messages from what they intended.

Consumers use various features of a product as signals for quality. Several researchers (Oude Ophuis \& Van Trijp, 1995; Steenkamp, 1990; Szybillo \& Jacoby, 1974; Zeithmal, 1988) dichotomize product related features into extrinsic cues and intrinsic cues which consumers use as signals when evaluating product quality. Intrinsic cues are considered as part of the physical product. Therefore, they cannot be altered without also altering the physical product itself, such as appearance, color, size, etc., whereas extrinsic cues are closely associated to the product while not necessarily be the physical part of it (e.g., 
price, store name, etc., Oude Ophuis \& Van Trijp, 1995; Yan, Sengupta, \& Wyer Jr., 2014). As such findings suggest, price is one of the signals that consumers use when they evaluate product quality. Prior research suggests that consumers use extrinsic attributes more than intrinsic attributes for their initial purchase, in case when they have no available intrinsic cues, when they need to exert more effort or time to evaluate such cues than they expected, or when they find evaluations of quality difficult (Zeithmal, 1988).

\subsection{Impact of Price Promotion on Perceived Quality}

Marketing researchers have argued that price serves as an important cue in the marketplace (Gijsbrechts, 1993) as in indicates the amount of money required to sacrifice for consumers' consumption needs (Völckner \& Hofmann, 2007). That is, price indicates a financial burden to consumers, and price is negatively related to purchase probabilities (Erickson \& Johansson, 1985). Whereas, price is perceived in a broader sense by many consumers, in that they use it as a cue of product quality (e.g., Völckner \& Sattler, 2005; Etgar \& Malhotra, 1981). Such theoretical and empirical evidence supports the idea that lower price negatively influences consumers' perceived quality overall, though the relationship varies across different factors such as brand name, product type, etc. This price-perceived quality theory supports the negative impact of a price promotion on consumers' perceived quality of a product; as a price promotion implies lower price, consumers' perception of product quality will decrease as well.

Also, attribution research, which is concerned with various aspects of causal inferences in human behavior, deals with a wide range of consumer behavior issues including attempts to explain the link between consumers' attitudes and behaviors (Folkes, 1988). According to the theory, consumers think of causes for managerial actions (Folkes, 1988); when consumers see a firm's promotion, they think the cause for the promotion is a decrease in product quality. Dodson et al. (1978) demonstrate that if consumers purchase a brand or product on a deal, they are more likely to attribute their purchase to the deal (i.e., they purchased the product because of the deal) rather than to positive attitude toward the product, compared to when a consumer buys a brand at full price. Raghubir \& Corfman (1995) argue that a cause for a promotion can be attributed to "internal" (i.e. brand-specific factors) when a firm's behavior is distinct from what others do. It supports the idea that when there is no other information available to judge product quality, a price promotion serves as a negative cue for consumers' quality perceptions.

Previous literature on the link between a price promotion and consumers' product evaluation has shown that a price promotion serves as a negative cue, especially when consumers do not have other product attributes information available to evaluate a product's quality. Specifically, past promotion behavior of a promoted product, consumers' expertise in a promoted product and competitive products' promotion behavior in an industry influence the relationship between price promotions and consumers' perceived product quality (Raghubir \& Corfman, 1999). Raghubir, Inman, \& Grande (2004) suggest product type, target segment, and types of promotions influence the impact of promotions on consumers' perception for a product. Raghubir (1995) argues that when there is high variation in quality among products the negative impact of a price promotion on consumers' perception for a product quality decrease.

Prior research findings mentioned above are largely focused on different promotion types, behaviors of firms or competitors, and their impact on consumers' perceived product quality (Raghubir \& Corfman, 1999; Raghubir et al., 2004). Such findings also focus on specific consumer types, such as consumers' expertise or demographic (Raghubir et al., 2004). Also, they suggest that providing information can reduce the negative effect of a price promotion on consumers' perceived quality of a product. To our knowledge, however, few studies have looked at how the relationship between a promoted product and other products in a choice set influences the effect of a price promotion on consumers' perceived quality of a product. More specifically, we attempt to examine how consumers' ability to process product attributes information - i.e., how easily consumers can process and compare product attributes information in a choice set — influences the link between price promotions and consumers' perceptions of a product's quality.

According to Raghubir et al. (2004), consumers' willingness to make efforts to process information is more prone to utilize other details about the deals as source of information. This implies that in some situations, consumers will be more involved in processing product information than others, even if their choice sets or shopping environments do not change. In line with such idea, we attempt to study how the relationship between attributes of a product with competing products' affects how much they are involved in comparing products in the choice set, thereby affects the price-quality relationship. Firms should consider the type of product they sell, characteristics of their target consumers, or competitive firms' promotion strategy in the market when they offer promotion. However, what is largely overlooked is how consumers' perception of product quality can change due to the context other than the product itself. Therefore, we argue that knowing the product and target characteristics and competitors' promotion strategy is not enough to implement an effective promotion strategy because 
consumers also pay attention to product attributes and compare their product with competitors' products when evaluating product quality.

Perceived quality is comparative; Steenkamp (1990) suggests that the perceptions of product quality may be influenced by competing contexts of other brands available in the market. For instance, the perceptions of brand A's quality relative to brand B changes by the introduction of brand C, dominated by brand A but not by brand B (Huber, Payne, \& Puto 1982).

Also, a choice set influences consumers' evaluation process of product quality. As the number brands available increases, consumers are more likely to adopt a two-stage strategy when evaluating quality of the brand (Payne, 1976; Lussier \& Olshavsky, 1979). Zeithmal (1988) also suggests that cosumers evaluate quality in a comparison context. According to her study, evaluation is a comparative process in which "a product quality is evaluated as high or low depending on its relative excellence or superiority among products or services that are viewed as substitutes by the customer". Therefore, we argue that it is critical to acknowledge that consumers' perceptions of product quality are influenced by what its competing products are in their choice set and its relationship with these competing products.

This research shows that when consumers have greater ability to process product attribute information then the negative effect of a price promotion on consumers' perceived product quality will decrease. We argue that product attributes' alignability with competing products will play such a role of providing consumers the ability to process product attribute information.

\subsection{Attribute Alignability}

Research in structural alignment theory suggests one way of categorizing attributes into alignable and non-alignable attributes. Attributes are alignable when two or more competing products share common attributes which enable direct comparison. In contrast, attributes are non-alignable when one product has attributes along a unique dimension which are not shared with other products' attributes (Medin, Goldstone, \& Markman 1995). Choice difficulty has been found to be a function of the number of different attributes for each alternative (Shugan, 1980). Also, past research findings suggest that nonalignable attributes are more difficult to process, so the decision maker is more likely to focus on the easily-processed alignable attributes (Zhang \& Markman, 2001; Zhang \& Fitzsimons, 1999). Therefore, these findings provide support for the positive relationship with product attributes alignability with consumers' ability to process product attributes information, by making it easier for consumers to compare product attributes.

When product attributes of a promoted product are alignable with competitive product in a choice set, consumers can easily compare competing products on common attributes as compared to when product attributes are non-alignable. Consumers can process more information of product attributes when they evaluate product quality and pay less attention to price information.

H1: Attribute alignability among competing products reduces difficulty in comparisons of competing products, and therefore increases attention to non-price attributes and reduces attention to price information in the choice set.

As suggested in H1, if consumers focus more on non-price product attributes and less on price information when product attributes are more alignable, the role of a price discount will decrease when consumers making judgments of the product's overall quality. That is, consumers will be less influenced by a price information when evaluating product quality. While previous research findings suggest that price promotions decrease a product's perceived quality, attribute alignability will play a role to reduce such negative impact. Also, since price works as a signal when other information is missing or difficult to process, we expect a price promotion's negative effect on consumers' perceived product's quality will decrease under greater attribute alignability.

H2: Attribute alignability among competing products reduces the negative effect of a price promotion on consumers' perceptions of product quality.

\section{Research Methods and Materials}

\subsection{Study 1: The Impact of Attribute Alignability on Decrease in Attention to Price Information via Increase in Attention to Non-Price Information}




\subsubsection{Overview}

In order to test the first hypothesis, we developed a scenario about a purchase decision process. The two different versions scenario describe attributes and the price of a Bluetooth speaker for a new place. The scenarios differ in the level of product attribute alignability by varying the number of alignable attributes in the two products, while the total number of product attributes and price information remain the same in the two conditions. The developed scenarios were used to test if the difference in the level of attribute alignability among competing products in a choice set influences difficulty in comparisons among product attributes, thereby lead to changes in the level of attention on non-price attributes in the decision-making process (see Appendix 1).

\subsubsection{Procedure}

Ninety-nine respondents participated through Amazon Mechanical Turk and completed this between-subjects experiment in exchange for monetary compensation. Respondents were randomly assigned to one of the two conditions (i.e., high vs. low alignability) and required to read a scenario. In the scenario, they were about to move to a new apartment and planning to buy a new Bluetooth speaker to be placed in the new home. The scenario describes two brands of the Bluetooth speaker along with product attributes (e.g., size, compatibility, color, etc.) and price information. The two conditions differed in the level of alignability of the two competing products' attributes, such that high alignability condition has all the attributes described in the scenario alignable while low alignability condition has only one attribute alignable among the competing products. After reading the descriptions, participants answered the following questions about their choice (i.e., "which of the two brands of the Bluetooth speaker products would you purchase for your new place?"), perceived quality of the product by each brand (i.e., "how would you rate the quality of sound of Bluetooth speakers by each brand?"), and the decision process (e.g., difficulty in comparisons of the two Bluetooth speaker brands, importance of each product attribute to participants when making the decision, etc.). All responses were captured on seven-point Likert-type scales. The price-quality relationship literature uses single-item scales to evaluate perceived quality (e.g., Yan \& Sengupta 2011). We also found support for the use of single-item scales from a study by Szymanski and Henard (2001) in the service evaluation literature, where they argue that the use of holistic, single-item measures pertaining to an overall evaluation allows customers to weigh their own criteria in determining their satisfaction, thus potentially making those measures appropriate.

\subsubsection{Results and Discussions}

First, we found a significant difference in participants' level of difficulty in comparing the two options Bluetooth speakers when making a purchase decision in the two conditions. A one-way ANOVA reveals that participants rated difficulty of comparisons lower in the high alignability condition compared to the low alignability condition $(\mathrm{Mhigh}=2.57, \mathrm{SDh}$ igh $=$ 1.49; Mlow $=3.22$, SDlow $=1.59 ; \mathrm{F}(1,97)=4.43, \mathrm{p}=.04)$. The result indicates that participants find it less difficult to compare the competing products when product attributes are more alignable.

Next, we conducted a mediation analysis to see if participants experience less difficulty to compare the products and thereby be able focus more on non-price attributes in the decision process. The bootstrapping procedure (PROCESS model 4, Hayes 2017; Hayes \& Preacher 2014) was used with 5,000 samples. The effect of attribute alignability on difficulty in comparisons was negative and significant $(\mathrm{b}=-.65, \mathrm{se}=.31, \mathrm{t}=-2.10, \mathrm{p}=.04)$ and the effect of difficulty on importance of sound quality was negative and significant $(b=-.11, \mathrm{se}=.06, \mathrm{t}=-1.70, \mathrm{p}=.09)$. While there is no significant direct effect of attribute alignability on importance of sound quality (point estimate $=-.04,90 \% \mathrm{CI}=[-.37, .29]$ ), an indirect effect through difficulty in comparisons was found to be significant (point estimate $=.07,90 \% \mathrm{CI}=[.00, .19]$, consistent with our prediction (see Figure 1).

In order to consider and rule out the possibility that the study results differ due to external factors such as difference in attractiveness of the product that leads to choice of one option over the other option, other than the main study variable, we also tested the difference in perceived quality and choice among the two products in the two conditions. We found no significant difference in perceived quality of the first option $(p=.88)$, the second option $B(p=.91)$, or choice of one option over the other $(\mathrm{p}=.93)$. 


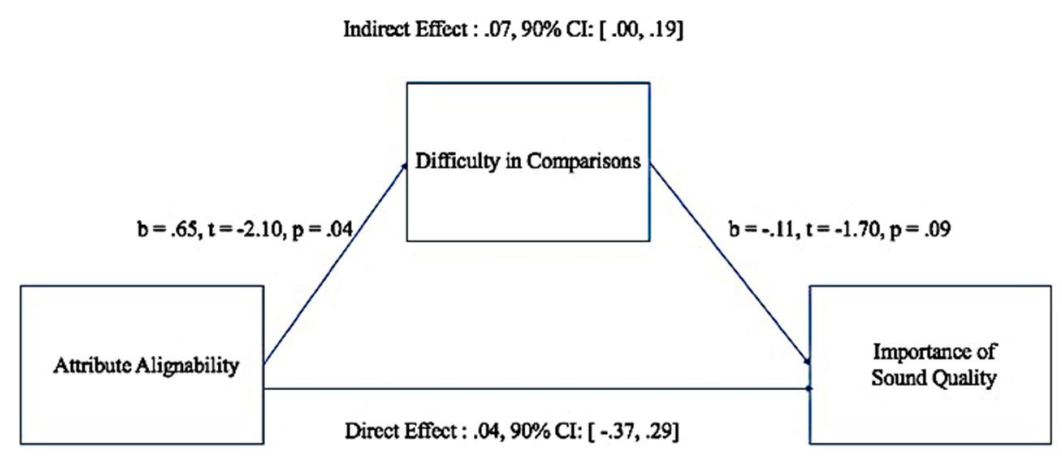

Figure 1: Difficulty in Comparisons as a Mediator Between Attribute Alignability and Importance of Sound Quality

\subsection{Study 2: Attribute Alignability as a Moderator of the Relationship between Price Promotion and Perceived Quality}

\subsubsection{Overview}

The purpose of study 2 is to 1) test the second hypothesis and 2) extend our findings to a different product category to see if the results are generalized across different product categories and different levels of promotions. In study $2 \mathrm{~A}$, we adopted the Bluetooth speaker scenario used in study 1 and extended the scenario with price discount information in one option. Then, we tested the interaction effect of attribute alignability and promotion on perceived quality. Study $2 \mathrm{~B}$ follows the same process with 1) a different scenario and 2) different levels of price discounts. We created a scenario about a purchase decision among two popcorn packs, where the number of alignable attributes vary in the two conditions.

\subsubsection{Study 2A - Procedure}

One-hundred and thirteen respondents recruited through Amazon Mechanical Turk participated in this 2 (promotion: high $(50 \%)$ vs. low $(10 \%))$ x 2 (alignability: high vs. low) between-subjects experiment. Similar to the previous study, respondents were assigned to one of the four conditions (i.e., promotion $\mathrm{x}$ alignability) and required to read a scenario. Same as study 1 , they read a scenario regarding a new Bluetooth speaker to be placed in the new home which describes two brands of the Bluetooth speaker along with product attributes (e.g., size, compatibility, color, etc.) and price information. Different from study 1, we included different levels of promotion information on the first option of the Bluetooth speaker by adding one more phrase (10\% vs. $50 \%$ off this week) under the price information. Therefore, the two Bluetooth speakers had the same original price while the second option was discounted. The scenarios also differed in the level of alignability of the two competing products' attributes, such that high alignability condition has all the attributes described in the scenario alignable while low alignability condition has only one attribute alignable among the competing products (see Appendix 2). Similar to study 1 , after reading the descriptions, participants answered the following questions about their choice, perceived quality of the product by each brand, and the decision process using seven-point Likert-type scales.

\subsubsection{Study 2A - Results and Discussions}

An ANOVA analysis shows a significant interaction effect between attribute alignability and promotion on consumers' perceived quality of the Bluetooth speaker which is on price discount $(F(1,126)=2.98, p=.09$; see Figure 2$)$. The results support H2 that when attributes among competing products are more alignable, the price promotion's effect on perceived quality becomes less negative. However, we did not find a significant interaction effect of attribute alignability and promotion on perceived quality of the other product in the choice set, which is not on price discount $(\mathrm{F}(1,126)=.14, \mathrm{p}>.7)$. 


\subsubsection{Study 2B - Procedure}

Ninety-two respondents recruited through Amazon Mechanical Turk participated in this 2 (promotion: high vs. low) $\mathrm{x} 2$ (alignability: high vs. low) between-subjects experiment. In order to test if the study 2A results are generalizable to different product categories, we developed a new scenario with a new product category. In the scenario, they were planning a class party on the weekend and about to purchase a microwave popcorn pack. The scenario describes two brands of popcorn pack along with product attributes (e.g., ingredients, flavor, etc.) and price information. Participants were randomly assigned to one condition out of the four different conditions and required to read a scenario. Same as study $2 \mathrm{~A}$, the scenario has four different versions: we included different levels of promotion information on the second option of the popcorn pack by adding one more phrase ( $5 \%$ vs. $50 \%$ off this week) under the price information. Therefore, the two popcorn packs had the same original price while the second option was discounted. The scenarios also differed in the level of alignability of the two competing products' attributes, such that high alignability condition has all the attributes described in the scenario alignable while low alignability condition has only one attribute alignable among the competing products (see Appendix 3). After reading the descriptions, participants answered the following questions about their choice (i.e., "which of the two brands of the popcorn packs would you purchase for the class party?"), perceived quality of the product by each brand (i.e., "how would you rate the tastiness of the popcorn packs by each brand?" and "how would rate the overall quality of the popcorn packs by each brand?"), and the decision process.

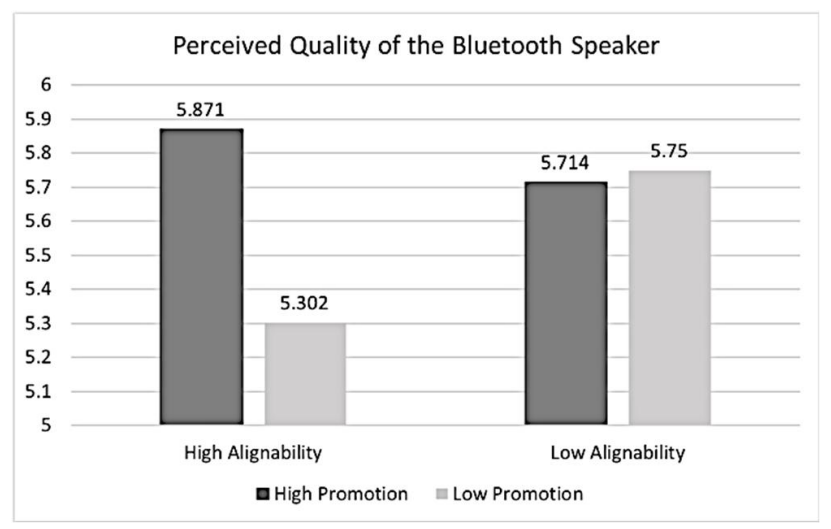

Figure 2: Interaction Effect Between Attruute Alignability and Promotion on Perceived Quality of the Promoted Bluetooth Speaker

\subsubsection{Study 2B - Results and Discussions}

Consistent with study 2A, an ANOVA analysis provides evidence of a significant interaction effect between attribute alignability and promotion on consumers' perceived tastiness of the popcorn pack on price discount $(\mathrm{F}(1,88)=2.83, \mathrm{p}=.096$; see Figure 3A). In addition, we measured the participants' perceived overall quality of the popcorn pack. The interaction effect between attribute alignability and promotion on consumers' perceived quality of the discounted popcorn pack was also significant $(\mathrm{F}(1,88)=4.79, \mathrm{p}=.032$; see Figure $3 \mathrm{~B})$. The results not only support $\mathrm{H} 2$, but also extend the results from study $2 \mathrm{~A}$ to a different product category and a different promotion range. However, we did not find a significant interaction effect of attribute alignability and promotion on perceived tastiness of the other product in the choice set, which is not on price discount $(F(1,88)=1.35, p>.2)$. In a similar vein, the interaction effect of attribute alignability and promotion on perceived quality of the other product was also not significant $(\mathrm{F}(1,88)=2.27, \mathrm{p}>.1)$. 


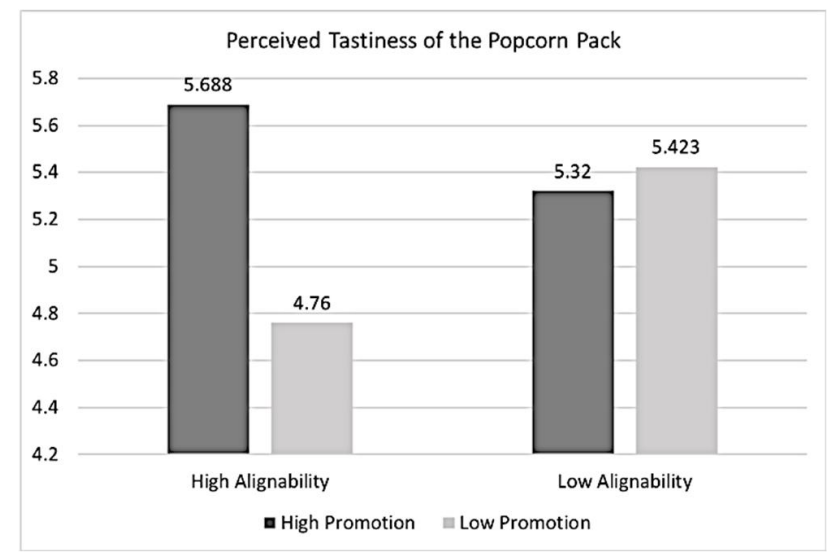

Figure 3A: Interaction Effect Between Attribute Alignability and Promotion on Perceived Tastiness of the Promoted Popcom Pack

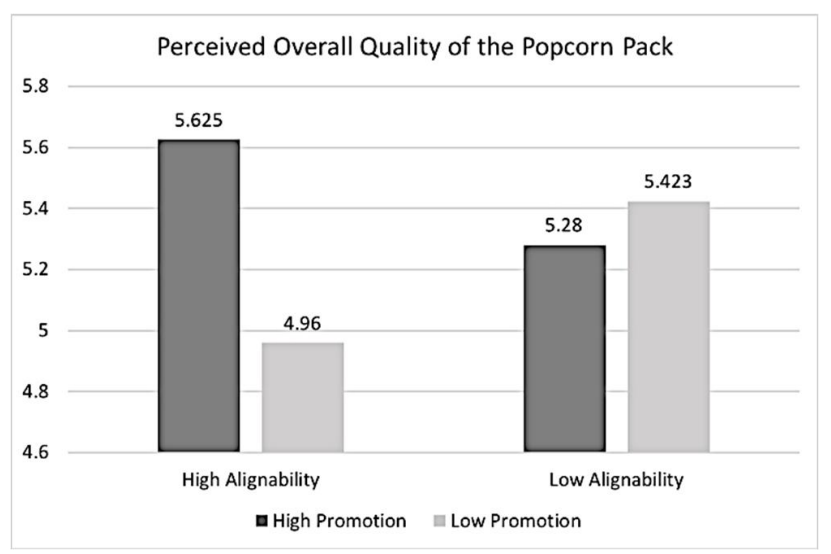

Figure 3A: Interaction Effect Between Attribute Alignability and Promotion on Perceived Overall Quality of the Promoted Popcorn Pack

\section{General Discussions}

This research explores the idea that not only a product's attributes but also its relationship with other products within a choice set influences consumers' perceived quality of the product. More specifically, we examined the role of a promoted product's attribute alignability with competing products in a choice set on the link between price promotion and perceived quality. First, we examined the role of attribute alignability among competing products in a choice set. In order to test the first hypothesis, we developed a scenario about purchasing a Bluetooth speaker among two options. The scenario has two conditions where the level of attribute alignability varies. In the high alignability condition, all the product attributes described in the two options of the speaker were alignable (i.e., share common attributes that enable direct comparisons), whereas only one of the attributes among the two options was alignable in the low alignability condition. The results of study 1 show that participants experienced less difficulty in comparing the two speakers and thereby lead to focus more on non-price attributes when making a purchase decision in the high alignability condition than the low alignability condition.

Next, this research shows how a promoted product's attribute alignability with competing products in a choice set influences the effect of the product's promotion on perceived quality. In study $2 \mathrm{~A}$, we adopted the scenario from study 1 to test $\mathrm{H} 2$ and included different levels of price discounts in one of the two options. Using a 2 (promotion: high vs low) $\mathrm{x} 2$ (alignability: high vs low), the study $2 \mathrm{~A}$ examined the role of attribute alignability on the relationship between a price promotion and perceived quality. A significant and positive interaction effect between attribute alignability and price promotion on perceived quality of the promoted option of the Bluetooth speaker shows that attribute alignability serves as a 
moderator that reduces the negative effect of a price promotion of on perceived quality. We further tested $\mathrm{H} 2$ in study $2 \mathrm{~B}$ in a different product type using different levels of price discounts to see if findings in study $2 \mathrm{~A}$ are generalizable across different product categories. In study $2 \mathrm{~B}$, we developed a new scenario using two options of popcorn packs for a class party and found a significant and positive interaction effect between attribute alignability and price promotion on consumers' perceived quality of the discounted popcorn product. Therefore, the study 2B results also support the idea that attribute alignability serves as a moderator which makes the effect of a price promotion on perceived quality less negative. In both study $2 \mathrm{~A}$ and $2 \mathrm{~B}$, we also examined perceived quality of the other product which is not on promotion in the choice set, but found no significant effect of attribute alignability as a moderator.

\section{Theoretical and Managerial Implications}

This research makes contributions to the academic literature in the following ways. First, while previous research findings in the promotion literature focus mostly on the role of product itself (e.g, product type, framing, etc.) or consumers, few studies have looked at the role of other products within the market. However, consumers often consider multiple products in a choice set and make comparisons of them for purchase decisions. Moreover, consumers' perceptions of a product not only depend on the product itself but also comparisons with other products. This research explores the role of other products in the market, especially the relationship with the focal product to better understand the effect of price promotion on consumers' quality perceptions and choice. Second, in line with the previous literature, we show that consumers' responses toward price promotions have both directions. We contribute to the literature by showing that while the choice of a product can increase when discounts get larger, quality perceptions decrease. The results imply that consumers purchase a product for different reasons when the product is promoted, indicating that increased sales do not necessarily mean that consumers evaluate the product more favorably.

Firms need to think of their goals in the short term as well as the long term. Price promotions are known to be effective for sales increase at least in the short term. If the product is already at its mature stage and consumers have good knowledge about their product, then price promotions would work as a good strategy if firms want to increase sales. However, frequent use of price promotions without further considerations of what this strategy might cause to consumers' perceptions about their products could hurt the firms in the long term. If firms care about building a good brand image and want to deliver quality products, then they need to be cautious about using price promotions, especially if their products are not directly comparable to competitors in many attributes.

Moreover, firms need to reconsider how to present their product on the market. Our study findings demonstrate that a product with a price discount undermines consumers' quality perceptions especially when products' attributes are hardly comparable to each other. If firms want to use price promotions and want to keep the quality perception at the same time, our recommendations would be to add more comparable information in its advertising rather than non-comparable information. Often times firms demonstrate in their advertising messages how their products are better by highlighting something missing in the competitors' products. We argue that this is less effective as consumers have more difficulty in comparing competing products directly and thereby focus more on price information only. That is, they can provide product information which their competitive products also have, such that consumers can easily make comparisons between products in their choice set. For example, marketing managers can highlight their alignable attributes when conveying message to consumers. Explaining how their products (attributes) are better than competitors' attributes would be a good idea, rather than focusing on their "unique" or "new" attributes which are often times highlighted in advertisements. Providing more information that could be directly compared to others would offer consumers opportunities to learn more about the products on their own and not entirely dependent on price information to infer quality. In sum, by examining consumers' choice set, marketing managers can provide appropriate information about product attributes and enable consumers to make comparisons between their product and competitive products.

\section{Limitations and Future Research Directions}

Although our research suggests novel insights to marketers about how consumers' choice set influences the link between a price promotion and consumers' perceived quality of a product, there are several concerns worth attention.

First, this research does not consider whether consumers have knowledge or experiences of a promoted product prior to evaluation of quality. If consumers already have prior knowledge/experiences, then their evaluation process of product quality 
might not be based on examinations and comparisons of product attributes presented to them. In such cases, consumers' knowledge and experiences of a product will influence product evaluation and they might not use product attributes as a cue for product quality at all. If so, consumers will be less likely to compare product attributes and thus consumers' choice set, or situational context will not influence a price promotion's effect on consumers' perceptions of quality of a product.

Second, if each attribute's importance is different to consumers or they use different evaluation process when they evaluate product quality (ex: preferring products with popular brand name only or believing that price is the only cue which signals product quality), then consumers' choice set do not play an important role on the link between a price promotion and consumers' perceived quality of a product.

Also, although we examined consumers' perceptions of product quality, there are other signals of a price promotion on consumers' attitude or behavior, such as brand loyalty, satisfaction after purchase, perceived fairness of a deal, etc. Further research should examine how a price promotion affects different kinds of consumers' attitudes and behaviors.

\section{References}

Aaker, D. A. (2009). Managing brand equity. SimonandSchuster. Com.

Blattberg, R. C., \& Neslin, S. A. (1990). Sales promotion: Concepts, methods, and strategies. Englewood Cliffs, NJ: Prentice Hall.

Davis, S. J., Inman, J., \& McAslister, L. (1992). Promotion has a negative effect on brand evaluations: Or does it? Additional disconfirming evidence. Journal of Marketing Research, 29 (February), 143-148.

Dodds, W. B., \& Monroe, K. B. (1985). The effect of brand and price information on subjective product evaluations. Advances in Consumer Research, 12(1), 85-90.

Dodson, J. A., Tybout, A. M., \& Sternthal, B. (1978). Impact of deals and deal retraction on brand switching. Journal of Marketing Research, 15(February), 72-81.

Erickson, G. M., \& Johansson, J. K. (1985). The role of price in multi-attribute product evaluations. Journal of Consumer Research, 12 (September), 195-199.

Etgar, M., \& Naresh K. Malhotra (1981). Determinants of price dependency: Personal and perceptual factors. Journal of Consumer Research, 8 (September), 217-222.

Garvin, D. A. (1984). What does “product quality” really mean? Sloan Management Review, 26 (Fall), 25-43.

Gijsbrechts, E. (1993). Prices and pricing research in consumer marketing: Some recent developments. International Journal of Research in Marketing, 10(June), 115-151.

Gupta, S. (1988). Impact of sales promotions on when, what, and how much to buy. Journal of Marketing research, 25(4), $342-355$.

Hayes, A. F. (2017). Introduction to mediation, moderation, and conditional process analysis: A regression-based approach. Guilford Publications.

Hayes, A. F., \& Preacher, K. J. (2014). Statistical mediation analysis with a multicategorical independent variable. British Journal of Mathematical and Statistical Psychology, 67 (3), 451-470.

Hjorth-Andersen, C. (1984). The concept of quality and the efficiency of markets for consumer products. Journal of Consumer Research, 11 (September), 708-718.

Huber, J., Payne, J. W., \& Puto, C. (1982). Adding asymmetrically dominated alternatives: Violations of regularity and the similarity hypothesis. Journal of Consumer Research, 9(June), 90-98.

Kalwani, M. U., \& Yim, C. K. (1992). Consumer price and promotion expectations: an experimental study. Journal of Marketing Research, 29(February), 90-100.

Lichtenstein, D. R., \& Burton, S. (1989). The relationship between perceived and objective price-quality. Joumal of Marketing Research, 26(November), 429-443.

Lussier, D. A., \& Olshavsky. R. W. (1979). Task complexity and contingent processing in brand choice. Journal of Consumer Research, 6(September), 154-165.

Medin, D. L., Goldstone, R. L., \& Markman, A. B. (1995). Comparison and choice: Relations between similarity processes and decision processes. Psychonomic Bulletin \& Review, 2 (March), 1-19.

Monroe, K. B., \& Krishnan, R. (1985). The effect of price on subjective product evaluations. Perceived Quality: How Consumers View Stores and Merchandise, 209-232.

Neslin, S. A. (2002). Sales promotion. Handbook of marketing, 310-338.

Oude Ophuis, P. A., \& Van Trijp, H. (1995). Perceived quality: a market driven and consumer oriented approach. Food quality and Preference, 6(3), 177-183.

Payne, J. W. (1976). Task complexity and contingent processing in decision making: An information search and protocol analysis. Organizational behavior and human performance, 16(August), 366-387.

Raghubir, P. J., Inman, J., \& Grande, H. (2004). The three faces of consumer promotions. California Management Review, 46(Summer), 23-42.

Raghubir, P. J., \& Corfman, K. P. (1995). When do price promotions signal quality? The effect of dealing on perceived service quality. $A C R$ 
North American Advances.

Raghubir, P. J., \& Corfman, K. (1999). When do price promotions affect pretrial brand evaluations? Journal of Marketing Research, 36(May), 211-222.

Shugan, S. M. (1980). The cost of thinking. Journal of consumer Research, 7(September), 99-111.

Steenkamp, J. B. E. (1990). Conceptual model of the quality perception process. Journal of Business Research, 21 (December), $309-333$.

Szybillo, G. J., \& Jacoby, J. (1974). Intrinsic versus extrinsic cues as determinants of perceived product quality. Journal of Applied Psychology, 59(February), 74.

Szymanski, D. M., \& Henard, D. H. (2001). Customer satisfaction: a meta-analysis of the empirical evidence. Journal of the Academy of Marketing Science, 29 (1), 16-35.

Völckner, F., \& Hofmann, J. (2007). The price-perceived quality relationship: A meta-analytic review and assessment of its determinants. Marketing Letters, 18(July), 181-196.

Völckner, F., \& Sattler, H. (2005). Separating negative and positive effects of price with choice-based conjoint analyses. Marketing ZFP, 27 (JRM 1), 5-13.

Yan, D., \& Sengupta, J. (2011). Effects of construal level on the price-quality relationship. Journal of Consumer Research, 38(August), 376-389.

Yan, D., Sengupta, J., \& Wyer Jr, R. S. (2014). Package size and perceived quality: The intervening role of unit price perceptions. Journal of Consumer Psychology, 24(1), 4-17.

Zeithaml, V. A. (1988). Consumer perceptions of price, quality, and value: a means-end model and synthesis of evidence," Journal of Marketing, 52(July), 2-22.

Zhang, S., \& Markman, A. B. (2001). Processing product unique features: Alignability and involvement in preference construction. Journal of Consumer Psychology, 11(1), 13-27.

Zhang, S., \& Fitzsimons, G. J. (1999). Choice-process satisfaction: The influence of attribute alignability and option limitation. Organizational Behavior and Human Decision Processes, 77(March), 192-214. 


\section{Appendices}

Appendix 1: Stimuli Used in Study 1

\begin{tabular}{|c|c|c|}
\hline \\
\hline \multirow{6}{*}{ High Alignability Condition } & Brand A (\$69.99) & Brand B (\$69.99) \\
\hline & Playtime: 12 hrs & Playtime: 20 hrs \\
\hline & Weight: 1.84 pounds & Weight: 3.46 pounds \\
\hline & Compatible with: Phone & Compatible with: Phone, Tablet, TV \\
\hline & Waterproof: Yes & Waterproof: No \\
\hline & Available in: Black & Available in: Black, White, Blue, Pink \\
\hline \multirow{6}{*}{$\begin{array}{c}\text { Low } \\
\text { Alignability Condition }\end{array}$} & Brand A (\$69.99) & Brand B (\$69.99) \\
\hline & Playtime: 12 hrs & Playtime: $20 \mathrm{hrs}$ \\
\hline & Weight: 1.84 pounds & Compatible with: Phone, Tablet, TV \\
\hline & Available in: Black, White, Blue, Pink & Built-in Mic \\
\hline & Waterproof: Yes & Size: $11.8 \times 2.6 \times 5.2$ inches \\
\hline & Touch Control & Warranty: 2 years \\
\hline
\end{tabular}

Appendix 2: Stimuli Used in Study 2A

\begin{tabular}{|c|c|c|}
\hline \multirow{4}{*}{ High Alignability Condition } & Brand A (\$69.99) & $\begin{array}{c}\text { Brand B (\$69.99) } \\
10 \% / 50 \% \text { off this week }\end{array}$ \\
\cline { 2 - 3 } & Playtime: 12 hrs & Playtime: 20 hrs \\
\cline { 2 - 3 } & Weight: 1.84 pounds & Compatible with: Phone, Tablet, TV \\
\cline { 2 - 3 } & Compatible with: Phone & Waterproof: No \\
\cline { 2 - 3 } & Waterproof: Yes & Available in: Black, White, Blue, Pink \\
\hline \multirow{3}{*}{ Llignability Condition } & Available in: Black & Brand B (\$69.99) \\
& Brand A $\mathbf{( \$ 6 9 . 9 9 )}$ & $10 \% / 50 \%$ off this week \\
\cline { 2 - 3 } & Playtime: 12 hrs & Playtime: 20 hrs \\
\cline { 2 - 3 } & Weight: 1.84 pounds & Compatible with: Phone, Tablet, TV \\
\cline { 2 - 3 } & Available in: Black, White, Blue, Pink & Built-in Mic \\
\cline { 2 - 3 } & Waterproof: Yes & Size: $11.8 \times 2.6 \times 5.2$ inches \\
\cline { 2 - 3 } & Touch Control & Warranty: 2 years \\
\hline
\end{tabular}

Appendix 3: Stimuli Used in Study 2B

\begin{tabular}{|c|c|c|}
\hline \multirow{6}{*}{ High Alignability Condition } & Brand A \$3.99 & $\begin{array}{c}\text { Brand B \$3.99 } \\
5 \% / 50 \% \text { off this week }\end{array}$ \\
\hline & Sodium level: $160 \mathrm{mg}$ & Sodium level: $200 \mathrm{mg}$ \\
\hline & Time to prepare: 90 seconds & Time to prepare: 60 seconds \\
\hline & Calories per packet: 100 & Calories per packet: 80 \\
\hline & Protein: $3 g$ & Protein: $1 \mathrm{~g}$ \\
\hline & Strongly buttery flavor & Mild buttery flavor \\
\hline \multirow{2}{*}{$\begin{array}{c}\text { Low } \\
\text { Alignability Condition }\end{array}$} & Brand A \$3.99 & $\begin{array}{c}\text { Brand B \$3.99 } \\
5 \% / 50 \% \text { off this week }\end{array}$ \\
\hline & Sodium level: $160 \mathrm{mg}$ & Sodium level: $200 \mathrm{mg}$ \\
\hline
\end{tabular}




\begin{tabular}{|c|c|c|}
\hline \multirow{2}{*}{} & Tastes sweet & Time to prepare: 60 seconds \\
\cline { 2 - 3 } & Moisture proof packaging & Calories per packet: 80 \\
\cline { 2 - 3 } & Total fat per packet: $8 \mathrm{~g}$ & Protein: $1 \mathrm{~g}$ \\
\cline { 2 - 3 } & Total carbohydrates: $7 \mathrm{~g}$ & Mild buttery flavor \\
\hline
\end{tabular}

